\title{
EXTENDING THE SERVICE LIFE OF PAVEMENTS
}

\author{
Ivan GSCHWENDT ${ }^{*}$
}

\section{Abstract}

The cost of road construction and expenditures on the maintenance of pavements, i.e., their whole life cost, represents a lot of money. The paper describes a procedure for a pavement management system with degradation models and estimates the length of time for the rehabilitation of an asphalt pavement. Using a theory of pavement mechanics, we calculated the stresses and strains on the layers of two pavement models. High modulus asphalt concrete, an asphalt mix with a high binder content, and an asphalt mix with binder modifications are new road building materials. Prolonging the time for the rehabilitation of pavements is possible.

\section{Address}

1 Faculty of Civil Engineering, Slovak University of Technology in Bratislava, Slovak Republic

* Corresponding author: ivan.gschwendt@stuba.sk

\section{Key words}

- Pavement management system,

- Degradation model,

- Long life pavement.

\section{PAVEMENT DEGRADATION}

As with every construction, a road pavement starts to degrade from its initial use. Changes in the individual parameters (individually and together) that define a pavement's functionality and mechanical efficiency demonstrate its deterioration. Predictions of degradation and the development and changes in parameters that define a pavement's state are used in pavement management systems, decisions for pavement rehabilitation strategies, and plans that create the rehabilitation and reconstruction of pavements.

Presumptive changes in a certain parameter or characteristic of a total pavement state in relation to the number of load repetitions or time are defined by a degradation model. The general expression of certain parameters, depending on the number of load repetitions (or time), for a pavement's degradation is shown in Figure 1 (Gschwendt, I., 1999).

The standard procedure for determining the degradation of an existing pavement and for creating a degradation model is usually as follows: repeated measurements over some amount of time in space are determined, and pavement parameters in a particular road section or motorway are evaluated along with their relation to the traffic load or only the time of the road's usage. There is also a procedure which uses the theory and knowledge of the mechanics of degradation and the fatigue of road building materials and pavement structures. In cat- egorising the models, we distinguish models with an evaluation of one parameter or with evaluation models for the overall pavement state, i.e., with segregated and aggregated evaluations of a road pavement's condition.

From a practical point of view, degradation models related to surface roughness and a pavement's evenness in a cross section (ruts caused by traffic) are important. Also, the degradation of the me-

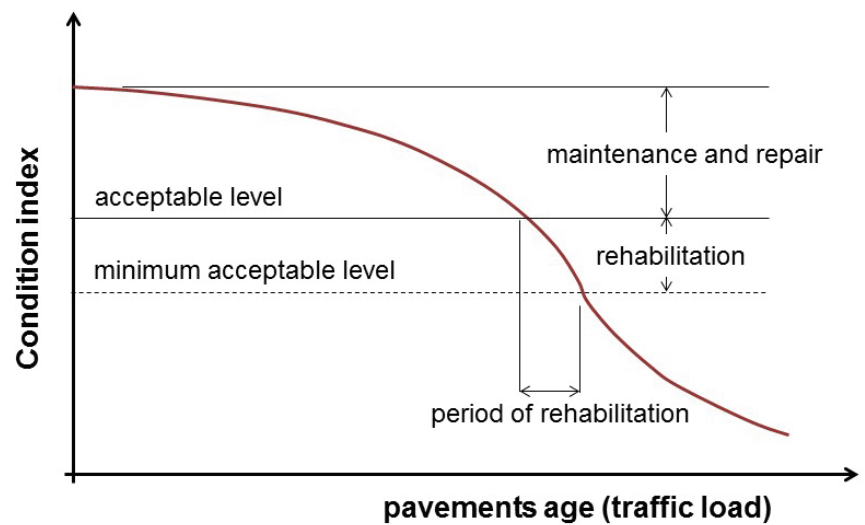

Fig. 1 Prediction model for deterioration of a pavement 
chanical efficiency (bearing capacity) and the intensity and scope of surface deteriorations matter. According to (Komacka, J., 2011), the succession over time of the data for a monitored variable parameter of a pavement state is the first step in the development of degradation models and the determination of degradation functions.

A derivation procedure for degradation models based on the records (and results) from visual condition surveys was presented in 1983 by MOLENAAR (Molenaar, A. A., 1983). Surveys on the visual condition of pavements were recorded on $100 \mathrm{~m}$-long road sections with defects so as to evaluate their extent $\left(\mathrm{m}, \mathrm{m}^{2}\right)$, intensity (width of cracks), depth of holes, etc. Through repeated surveys and evaluations of the record data for a timeline, changes in the data were obtained. Changes in certain parameters (with some simplification), can be expressed by the function:

$$
P_{(x)}=1-A\left(\frac{t}{T}\right)^{B}
$$

where: $A, B$ are parameters of the degradation of functions for certain types of deterioration, depending on the pavement structure,

$t \quad$ is time (years) expired from the initial use of a pavement till the date of its evaluation,

$T \quad$ is the assumed service life (proposed time) till the limit value of the parameter evaluated.

For the relative expression of parameters, $\mathrm{P}(\mathrm{x})=1.0$ after the pavement's construction. The ratio $t / T$ is called the time index; the loading index $\mathrm{n} / \mathrm{N}$ can be used as well.

Degradation models are used and have great importance in pavement management systems. The data for their creation are difficult to collect, and a methodology for the measurements must be strictly followed. Actual pavement management was discussed at the $15^{\text {th }}$ Seminar of I. Poliaček in 2010, which focused on Public-Private-Partnerships (PPP) projects (Team of authors, 2010). Diagnostic equipment, the results from repeated measurements of some pavement parameters, as well as developmental analyses of those parameters were described. In the development and deformation range, change (FWD) analyses, such as characteristics of a pavement's bearing capacity, were presented with some surprising results. The trend in the development of deformations (changes caused over time) was that in some cases, a deformation gradually got bigger, but in some other cases, it gradually got smaller (the bearing capacity increased).

One example of measurements of pavement roughness on selected road sections and the derivation of a degradation model is described in report (TPA, Ltd., 2009). The measurements were executed by a SKIDDOMETER FRICTION TESTER BV 11, while the friction scale was described by the parameter $\mathrm{Mu}$ (a non-dimensional parameter). The measurements were taken at speeds of 60 and $80 \mathrm{~km} / \mathrm{h}$; the temperatures were in a range of +5 to $+30^{\circ} \mathrm{C}$ on pavements with surface mixtures of $\mathrm{AC}(\mathrm{ABS}, \mathrm{ABH})$ and also SMA. The average $\triangle \mathrm{Mu}$ value, i.e. a change in $\mathrm{Mu}$, on all the sections (after elimination of any extreme values) was $0.6812 /$ year. The degradation model as a change in $\mathrm{Mu}$ for a longer time period is in Figure 2.

In applying the model, it is necessary to remember that there are roads with various traffic load classes (TLC I and II). The acceptable relative value of $\mathrm{Mu}$ is marked 0.80 as a relative expression; the average $\mathrm{Mu} 80$ is 0.58 . The relation curve in Figure 2 can be expressed by a polynomic function.

One issue is whether it is effective to create degradation models of all pavement state characteristics. More than 30 surface deteriorations have been recorded in visual surveys. This number of deteriorations is also in Technical specifications TP from 2014 in approximately in seven groups. One of the solutions can be an aggregate evaluation of several characteristics of pavement states (ISV, IPSV).

\section{PLANNING A PAVEMENT'S REHABILITATION}

As was stated at the beginning of the previous chapter, knowledge of a pavement's degradation is used in models which form a part of a pavement management system. A road pavement management system (PMS) also serves to provide actual solutions in planning a rehabilitation under certain technical and economic conditions. There are a number of activities which are connected to each other in a systematic approach to pavement management. The main activities are:

- pavement diagnostics (surveys of the visual condition, measurements of parameters),

- analysis of the measurement results and evaluation of the pavement state,

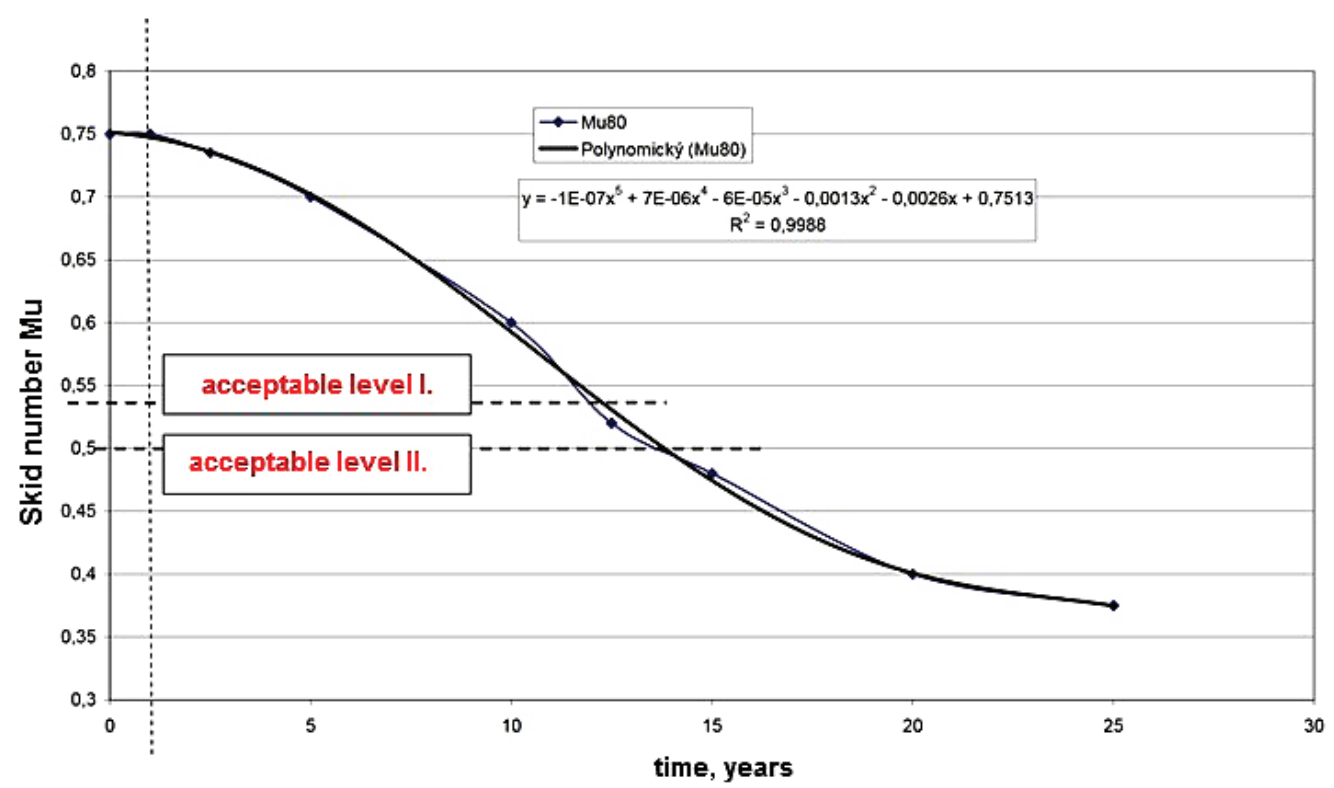

Fig. 2 Variation of surface friction over time (according to (TPA, Ltd., 2009)) 


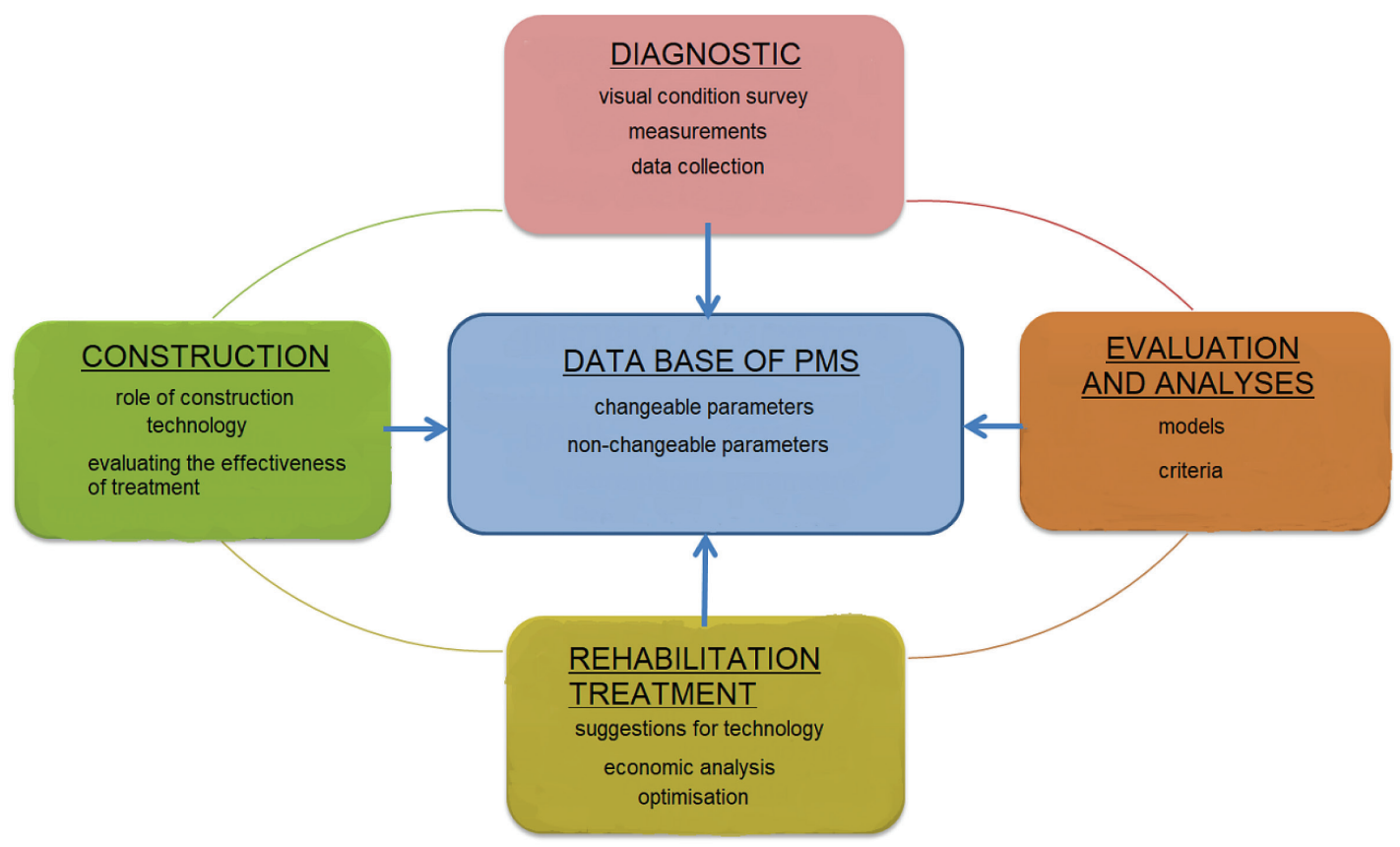

Fig. 3 Framework of a pavement management system

- application of the degradation models, proposed solutions, and selection of an optimal (technical as well as economic) solution,

- construction and application of technological procedures.

The main parts of a pavement management system and consequent actions are shown in Figure 3.

After the diagnostics are completed two questions have to be answered for a pavement's rehabilitation, i.e., "when" and "how". After measurement of the roughness and its evaluation according to coefficient $\mathrm{Mu}$, which is shown in Figure 2, it can be assumed that the roughness will reappear after 6 to 8 years. The range of the rehabilitation, i.e., the materials and technological procedures, is very broad. It includes:

- surface dressing - asphalt or emulsion, one-layer or two-layer,

- emulsion microsurfacing,

- microcoats,

- asphalt coats: thin, mastic, drainage,

- asphalt concrete, with standard or modified binders of various qualities for the wearing and binder course, base, or sub-base layer.

The paper in (Kolivoška, J., 2013) shows interesting data for the rehabilitation of pavements on II. and III. class roads. The technologies used are divided into 10 groups; however, only two of them are mostly used ( 30 to $52 \%$ of the constructions):

- the milling of a 20 to $40 \mathrm{~mm}$ of the existing asphalt pavement surface layer and the laying of one layer of 40 to $60 \mathrm{~mm}$ thick asphalt concrete,

- the milling of a 40 to $60 \mathrm{~mm}$ thick layer of the degraded surface of an asphalt pavement; the laying of a levelling layer of approximately 30 to $40 \mathrm{~mm}$ thick and the laying of a 40 to 60 mm thick asphalt concrete layer.

The investor (employer) demanded a warranty period of 5 to 7 years for the work. When no proper diagnosis and only the rehabilitation of the surface layer is done, then the prolongation of the pave- ment's service life is questionable. If we want to plan the rehabilitation of pavements on various road network sections, then according to the assumed service life of the materials and technologies, it is necessary to know and consider the traffic load (mainly the heavy load vehicles/ number of lorries).

In an effort to gain an overview and knowledge of the characteristics and behaviour of pavements from the point of view of their rehabilitation and service life, "LTPP System" (Long Term Pavement Performance), an international programme was run by the American organization, FHWA, from 1992-1997. Thirty-four countries participated in this programme. The overview contained protocols on climate conditions, traffic loads, material characteristics, and interpretations of pavement deteriorations. The results were mainly used in standards for material characteristics and for adjusting the design and calculation of pavement models (SHIPP).

\section{PAVEMENT STRUCTURES FOR A LONG SERVICE LIFE}

Solutions for the prolongation of a pavement's service life (and its serviceability) are also sought in the pavement mechanics sector through re-evaluations of the functions of certain layers in the standard layout and their material characteristics. Measures preventing the occurrence of permanent deformations and ruts from the base to the surface as well as measures for increasing the subgrade bearing capacity have been undertaken. In the standard layout of pavement layers, their functions and the resulting requirements for characteristics of materials are as follows:

- The upper layer of a surface constitutes a wearing course, which is exposed to the direct impact of vehicle wheels as well as climate conditions, the impact of water, and chemical thawing agents. The material has to have compressive strength, resistance to permanent deformations, resistance to polishing and abrasion, as well as resistance to water. There is a binder course under the wearing course, the aim of which is to create favourable conditions for the wearing course and to 
Tab. 1 Pavement structure on the R1

\begin{tabular}{|c|c|c|}
\hline Material & Symbol & Thickness \\
\hline Stone mastic asphalt & SMA 11, PMB 45/80-75 $\mathrm{mm}$ \\
\hline Asphalt concrete & AC 22 L, PMB 45/80-55 & $70 \mathrm{~mm}$ \\
\hline High modulus asphalt concrete & AC VT & $90 \mathrm{~mm}$ \\
\hline Mechanically bound aggregate & MSK 31.5 $\mathrm{G}_{\mathrm{B}}$ & $240 \mathrm{~mm}$ \\
\hline Crushed stone & ŠD 31.5 $\mathrm{G}_{\mathrm{C}}$ & $200 \mathrm{~mm}$ \\
\hline
\end{tabular}

transfer the impact of the load to the base. The vertical stress in the layer is compressive stress; at the bottom of the layer there can be radial tensile bending stress. The material has to resist permanent deformations.

- The base layers (upper and lower) are bearing layers. The materials have to demonstrate sufficient stiffness, tensile bending strength, and resistance to fatigue.

- A protective layer was initially used as a part of the structure for protecting the base against frost, but gravel sand as an untreated local material is not suitable. Unbound material also has to fulfill special requirements for drainage and filtration functions.

Reevaluating the functions of particular layers and, subsequently, the requirements for material characteristics, are focused on the goal of prolonging the service life of asphalt pavements (their serviceability). Knowledge concerning the degradation of asphalt pavements has confirmed that the most important attributes are permanent deformations (rutting) and the cracks which usually form at the bottom of the base layer and advance upwards. These are directly connected to the use of asphalt mixtures resistant to permanent deformations and mixtures resistance to repeated loads, e.g., fatigue.

At the beginning of the development of pavements with a long service life, it was generally recommended to design asphalt pavements with relatively thick layers from asphalt mixtures (more than 250 mm). In English literature they were called "a Full - Depth Asphalt Pavement". An example of constructing an asphalt pavement with a long service life (more than 30 years) in Slovakia was the execution of the R1 Nitra - Tekovské Nemce PPP project. For a design traffic load of $\mathrm{N}_{\mathrm{c}}=30.10^{6}$, a structure with standard layout and materials (TP $3 / 2009$ ) was initially designed. The contractor decided to modify it. As is shown in Table 1, the wearing and binder courses had asphalt concrete layers made from mixtures with a modified binder, while the base was a high modulus asphalt concrete (HMAC, in the literature it is called Enrobé á Module Elevé (EME)). The HMAC mixture was laid on MSK $31.5 \mathrm{G}_{\mathrm{B}}$ mechanically bound aggregate layer.

According to the selection of the asphalt mixture for the wearing course, binder course, or base layer, it can be stated that according to the STN EN 13108 standards, there is a line of materials which can be used for constructing pavements with a long service life. Besides asphalt concrete (AC), there are also BBTM and SMA. Recently, other mixtures have been used:

- A high modulus asphalt concrete (HMAC), which will be marked below as AC - VT,

- An asphalt mixture with a higher amount of binder, RBL (Rich Bottom Layer) in English, which will be marked as AC $\mathrm{P}+$,

- An asphalt mixture with a binder with increased content of polymer in the PMB, i.e., SBS, HiMA in English, which will be marked as $\mathrm{AC} \mathrm{PmB+}$.
Fatigue tests of the mixes with paving grade, polymer modified bitumen, and $\mathrm{RBL}(\mathrm{AC} \mathrm{P}+$ ) were realised and are described in (Bures at. al., 2017). The mixtures have characteristics which can be used in structures with a long service life, i.e., stiffness and resistance to fatigue ("a low degree of fatigue"). In the laboratories of the Czech Technical University in Prague and EUROVIA Services s.r.o., laboratory tests on the stiffness and fatigue of $\mathrm{AC}-\mathrm{VT}, \mathrm{AC} 10 \mathrm{P}$ and $\mathrm{AC}$ $\mathrm{P}+$ mixtures were performed. The stiffness modulus of the AC P+ mixture was a little bit lower (compared to the standard AC), but the mixture with the modified binder had a higher degree of stiffness. The fatigue tests showed that the resistance of the AC P+ mixture is higher and better than the resistance of the quality of the asphalt concrete (standard)

Selected characteristics of the $\mathrm{AC}-\mathrm{VT}$ and $\mathrm{AC} \mathrm{P}+$ mixtures are shown in Table 2 (according to (Mondschein at al., 2015)).

Tab. 2 Characteristics of the AC-VT, AC P+ mixtures

\begin{tabular}{|c|c|c|c|}
\hline Characteristics & AC - VT & AC P+ \\
\hline \multicolumn{2}{|c|}{ Asphalt binder amount $(96 \%)$} & 4.80 & 5.30 \\
\hline \multicolumn{2}{|c|}{ Maximum bulk density $\left(\mathrm{kg} / \mathrm{m}^{3}\right)$} & 2610 & 2563 \\
\hline \multicolumn{2}{|c|}{ Void fraction $(\%$ volume $)$} & 3.2 & 1.0 \\
\hline \multirow{2}{*}{$\begin{array}{c}\text { Stiffness modulus } \\
\text { IT - CY (MPa) }\end{array}$} & $0^{\circ} \mathrm{C}$ & 22322 & 21792 \\
\cline { 2 - 4 } & $15^{\circ} \mathrm{C}$ & 9150 & 7605 \\
\hline \multirow{2}{*}{$\begin{array}{c}\text { Permanent } \\
\text { deformation } \\
\text { resistance }\end{array}$} & $\begin{array}{c}27^{\circ} \mathrm{C} \\
\left(\mathrm{mm} / 10^{3} \mathrm{cycles}\right)\end{array}$ & 3588 & 2830 \\
\cline { 2 - 4 } & $\mathrm{PRD}_{\mathrm{AIR}}(\%)$ & 1.7 & 3.1 \\
\hline
\end{tabular}

The results of the laboratory tests of the characteristics of the "new" asphalt mixtures were analysed, whereby their use in structures with a long service life on experimental road sections was also evaluated. One of the largest tests was realised on the NCAT experimental track in Alabama, USA. The track has an oval shape and is $2.7 \mathrm{~km}$ long. The pavements had a layer made from HiMA - a mixture with a binder with a large percentage of modifier (up to 7\% SBS) and also $\mathrm{AC} \mathrm{L}$ and $\mathrm{AC}$ P. The pavement's construction was finished in 2009; the loading of the section lasted till 2014. A traffic load of $10.10^{6}$ design axes was considered. A total load of up to 20 million design axes was finally achieved on the renovated surface. When the tests were evaluated, two aspects with regard to solving the problem of the longer service life of pavements were shown. Mixtures which can be used for this purpose are: 
Structure LLP - A

\begin{tabular}{|l|l}
\hline & $\begin{array}{l}\text { Stone Mastic Asphalt } \\
\text { SMA } 11 \text { PMB 45/80-75 } \\
\text { High Modulus Asphalt } \\
\text { AC VT }\end{array}$ \\
Asphalt Mix - Rich Bottom \\
AC P+
\end{tabular}

Structure LLP - B

\begin{tabular}{|c|c|c|}
\hline $40 \mathrm{~mm}$ & $\begin{array}{l}\text { Stone Mastic Asphalt } \\
\text { SMA } 11 \text { PMB } 45 / 80-75\end{array}$ & $40 \mathrm{~mm}$ \\
\hline \multirow[t]{2}{*}{$100 \mathrm{~mm}$} & $\begin{array}{l}\text { High Modulus Asphalt } \\
\text { ACVT }\end{array}$ & $90 \mathrm{~mm}$ \\
\hline & $\begin{array}{l}\text { Asphalt Mix - HiMA } \\
\text { ACPm B }\end{array}$ & $100 \mathrm{~mm}$ \\
\hline $100 \mathrm{~mm}$ & $\begin{array}{l}\text { Cement Bound Granular Material } \\
\text { CBGM C }_{5 / 6}\end{array}$ & $140 \mathrm{~mm}$ \\
\hline \multirow{4}{*}{$180 \mathrm{~mm}$} & & \\
\hline & Macadam & \\
\hline & Š $31.5(45) G_{C}$ & $180 \mathrm{~mm}$ \\
\hline & $\mathrm{E}_{\%} / \mu=40 \mathrm{MPa}, 90 \mathrm{MPa}$ & \\
\hline
\end{tabular}

Fig. $4 L L P-A$ and $L L P-B$ pavement structures

Tab. 3 Design (calculation) parameters of the selected asphalt mixtures

\begin{tabular}{|c|c|c|c|c|c|c|c|c|c|}
\hline \multirow{2}{*}{ Asphalt mixture } & \multicolumn{3}{|c|}{ Elasticity modulus E (MPa) } & \multicolumn{3}{c|}{ Poisson's ratio $\boldsymbol{\mu}$} & \multicolumn{3}{c|}{ Tensile bending strength $\mathbf{R}(\mathbf{M P a})$} \\
\cline { 2 - 11 } & $\mathbf{0}^{\circ} \mathbf{C}$ & $\mathbf{1 1}{ }^{\circ} \mathbf{C}$ & $\mathbf{2 7}^{\circ} \mathbf{C}$ & $\mathbf{0}^{\circ} \mathbf{C}$ & $\mathbf{1 1}{ }^{\circ} \mathbf{C}$ & $\mathbf{2 7}^{\circ} \mathbf{C}$ & $\mathbf{0}^{\circ} \mathbf{C}$ & $\mathbf{1 1}^{\circ} \mathbf{C}$ & $\mathbf{2 7}^{\circ} \mathbf{C}$ \\
\hline AC surfacing & 7,500 & 5,500 & 3,000 & 0.21 & 0.30 & 0.40 & 4.0 & 3.1 & 1.4 \\
\hline SMA & 7,500 & 6,000 & 3,750 & 0.21 & 0.30 & 0.40 & 4.0 & 3.2 & 1.75 \\
\hline AC base, PMB & 5,700 & 4,600 & 2,800 & 0.21 & 0.30 & 0.40 & 3.4 & 2.8 & 1.3 \\
\hline AC VT & 9,000 & 6,000 & 3,600 & 0.20 & 0.30 & 0.40 & 4.0 & 3.2 & 1.75 \\
\hline
\end{tabular}

- asphalt mixtures with a binder with a high percentage of modifier $(\mathrm{AC} \mathrm{PmB}+)$; they are constructed in the base layer, because of their good resistance to fatigue,

- asphalt mixtures with a high degree of stiffness, used in the binder course or base layer, because of their resistance to the creation of permanent deformations.

In (Gajewski at. al., 2016), a simple method was proposed to estimate the bearing capacity of a multilayer pavement structure, including the degradation of its constituent materials. With the aim of analysing the stresses and deformations of the "new" materials together with gaining a basis for decision making through their use, we performed calculations on two pavement structure models of asphalt pavements:

- LLP A (Long Life Pavement A) pavement model with an asphalt concrete layer with a high degree of stiffness and a mixture layer with a higher percentage of binder,

- LLP B (Long Life Pavement B) pavement model with an asphalt mixture layer with a binder with a high content of modifier.

The pavement structure schemes are in Figure 4.

Inputs to the LAYMED calculation programme were modified so that we would be able to monitor the vertical and radial stress processes in the layers.
The design (calculation) parameters of the selected asphalt mixtures were derived and are shown in Table 3.

From the results of the stress and radial deformation calculations, a list for three temperature states of the asphalt layers was derived: $0^{\circ} \mathrm{C}, 11^{\circ} \mathrm{C}$ and $27^{\circ} \mathrm{C}$. Figures 5 and 6 have tables that show stress values only for the $11^{\circ} \mathrm{C}$ state and schemes of the distribution of the vertical stress $\sigma_{z}$ and radial stress $\sigma_{r}$.

The highest radial tensile bending stress in the LLP A structure was in the $\mathrm{AC} \mathrm{P}+$ layer with a temperature of $11^{\circ} \mathrm{C}$ and also in winter with a temperature of $0^{\circ} \mathrm{C}$, because of the high value of $\mathrm{E}$ (MPa). In the case of increasing the bearing capacity of the base layer to $90 \mathrm{MPa}$, this stress will increase from 13 to $15 \%$. The stability of the mechanically bound aggregates is sufficient in a combination with the improved base layer; the radial stress is only $0.0772 \mathrm{MPa}$.

In the LLP B structure (Fig. 6), the radial stresses in the AC- VT and $\mathrm{AC} \mathrm{PmB}+$ layers are higher than in LLP A. With a temperature of $11^{\circ} \mathrm{C}$ in the AC-VT layer, it is 0.163 and $0.172 \mathrm{MPa}$; in the AC $\mathrm{PmB}+$ layer it is 0.752 and $0.819 \mathrm{MPa}$. A simple comparison of the stresses in the LLP A and LLP B layers leads from the point of the service life to a better evaluation of the first one; provided that there is the $\mathrm{AC}-\mathrm{VT}$ mixture under SMA in the wearing course and with the $\mathrm{AC} \mathrm{P}+$ mixture in the base layer.

As for the traffic load which can be carried by the pavement until its deterioration, the equation with the formulation of the number of 


\begin{tabular}{|c|c|c|c|c|c|}
\hline Vrstva & $\begin{array}{c}\text { Hrúbka } \\
\text { vrstvy } \\
\text { (mm) }\end{array}$ & $\stackrel{2}{Z}$ & $\begin{array}{c}\sigma_{2} \\
(\mathrm{MPa})\end{array}$ & $\begin{array}{c}\sigma_{f} \\
(\mathrm{MPa})\end{array}$ & $\varepsilon_{q}$ \\
\hline \multirow{2}{*}{1} & \multirow{2}{*}{40} & 0 & -0.600 & $-0.104 \mathrm{E} 1$ & $-0.916 \mathrm{E}-4$ \\
\hline & & 40 & -0.572 & -0.632 & $-0.452 E-4$ \\
\hline \multirow{2}{*}{2} & \multirow{2}{*}{100} & 40 & -0.574 & -0.631 & $-0.449 E-4$ \\
\hline & & 140 & -0.295 & 0.119 & $0.286 E-4$ \\
\hline \multirow{2}{*}{3} & \multirow{2}{*}{100} & 140 & -0.295 & $0.617 \mathrm{E}-1$ & $0.286 \mathrm{E}-4$ \\
\hline & & 240 & $-0.824 \mathrm{E}-1$ & 0.526 & $0.854 \mathrm{E}-4$ \\
\hline \multirow{2}{*}{4} & \multirow{2}{*}{180} & 240 & $-0.824 \mathrm{E}-1$ & $0.408 \mathrm{E}-1$ & $0.854 E-4$ \\
\hline & & 420 & $-0.241 \mathrm{E}-1$ & $0.778 \mathrm{E}-1$ & $0.106 \mathrm{E}-3$ \\
\hline
\end{tabular}

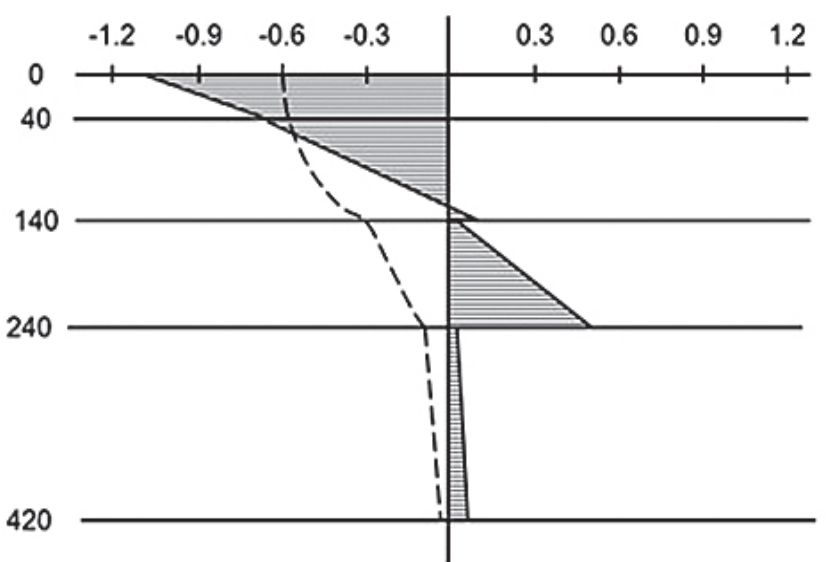

Fig. 5 Distribution of stress in the LLP A structure

\begin{tabular}{|c|c|c|c|c|c|}
\hline Vrstva & $\begin{array}{l}\text { Hrúbka } \\
\text { vrstvy } \\
\text { (mm) }\end{array}$ & $\stackrel{2}{2}$ & $\underset{(\mathrm{MPa})}{\sigma_{2}}$ & $\begin{array}{c}\sigma_{\mathrm{f}} \\
(\mathrm{MPa})\end{array}$ & $\varepsilon_{T}$ \\
\hline \multirow{2}{*}{1} & \multirow{2}{*}{40} & 0 & -0.600 & $-0.119 E 1$ & $-0.109 \mathrm{E}-3$ \\
\hline & & 40 & -0.564 & -0.697 & $-0.531 E-4$ \\
\hline \multirow{2}{*}{2} & \multirow{2}{*}{90} & 40 & -0.566 & -0.697 & $-0.529 E-4$ \\
\hline & & 130 & -0.283 & 0.163 & $0.331 \mathrm{E}-4$ \\
\hline \multirow{2}{*}{3} & \multirow{2}{*}{100} & 130 & -0.283 & $0.965 E-1$ & $0.331 \mathrm{E}-4$ \\
\hline & & 290 & $-0.548 \mathrm{E}-1$ & 0.752 & $0.118 \mathrm{E}-3$ \\
\hline \multirow{2}{*}{4} & \multirow{2}{*}{140} & 290 & $-0.548 \mathrm{E}-1$ & $0.614 E-3$ & $0.118 \mathrm{E}-3$ \\
\hline & & 370 & $-0.349 \mathrm{E}-1$ & $0.549 E-2$ & $0.385 E-4$ \\
\hline \multirow{2}{*}{5} & \multirow{2}{*}{180} & 370 & $-0.349 \mathrm{E}-1$ & $0.427 E-2$ & $0.385 E-4$ \\
\hline & & 550 & $-0.200 \mathrm{E}-1$ & $0.277 \mathrm{E}-1$ & $0.727 E-4$ \\
\hline
\end{tabular}

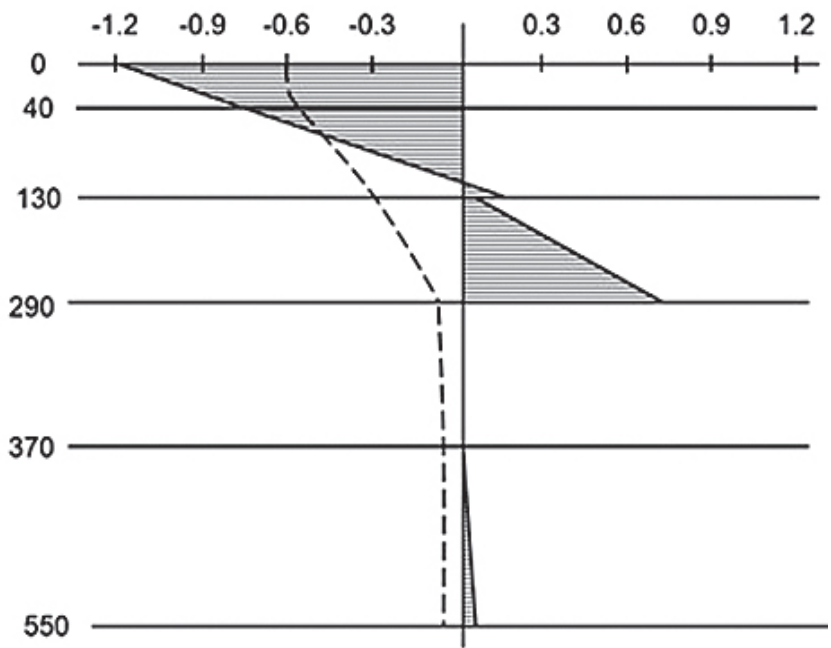

Fig. 6 Distribution of stress in the LLP B structure

design axes from the design method criteria in which the comparison of the stress and material strength in the critical layer is:

$$
\log N_{\text {bit }}=\frac{0.95 R_{i b i t}-\sigma_{\text {ribit }}}{0.12 R_{\text {ibit }}}
$$

where: $R_{i b i t} \quad$ is strength of AC,

$\sigma_{\text {ri bit }} \ldots$ radial stresses in AC layer.

The value of $\mathrm{N}_{\mathrm{C}}=6.681 .10^{6}$ on a subgrade with a bearing capacity of $90 \mathrm{MPa}$ and at a temperature of $11^{\circ} \mathrm{C}$ for the standard materials in the construction.

If AC-VT materials are used on $\mathrm{AC} \mathrm{P}+$, then:

$$
\mathrm{N}_{\mathrm{C}}=40.436 .10^{6}
$$

We can discuss the significant prolongation of the service life of a pavement or a higher number of design axes (the number of heavy vehicles) till the pavement deteriorates.

\section{CONCLUSION}

The extension of the service life or the required level of serviceability of pavements and the terms of their rehabilitation has great economic importance. When solving problems of how to design and build asphalt pavements with a long service life (e.g., a Long Life Pavement) and with longer periods for the rehabilitation of their serviceability, the following must be monitored:

- characteristics of road building materials, mainly of asphalt mixtures, their resistance to permanent deformations and resistance to repeated loading (fatigue),

- the composition of the pavement layers and the allocation of stresses and deformations in their structure (from the point of view of pavement mechanics),

- the importance of the improvement of the base and the impact of increases in its bearing capacity on stresses in the pavement.

The paper describes calculations of two models of asphalt pavements in which layers from non-standard asphalt mixtures were proposed: 
- $\mathrm{AC}-\mathrm{VT}$ (HMAC) high modulus asphalt concrete,

- RBL (Rich Bottom Layer) asphalt mixture with a higher amount of binder,

- HiMA (Highly Modified Bitumen) asphalt mixture with a binder with a high content of modifier.

The LLP A pavement model had a wearing course of SMA, an asphalt concrete layer with a high degree of stiffness, and an asphalt mixture with a higher percentage of binder. The LLP B pavement model had a wearing course of SMA, except for a layer with a high degree of stiffness and/also a layer with a high percentage of modifier in the asphalt binder. The physical - mechanical characteristics of the material which were the input data in the calculation programme were designed (derived). From the point of view of the assumed service life, simple comparison of the stress values in the LLP A and LLP B structures leads, to a better evaluation of the first one; the SMA on the wearing layer, the $\mathrm{AC}-\mathrm{VT}$ mixture and the $\mathrm{AC} \mathrm{P}+$ on the base layer. The importance of the base layer's improvement was significant, and the aim is to improve the bearing capacity. A bearing capacity of 90 $\mathrm{MPa}$ can, for example, be achieved by a $30 \mathrm{~cm}$ crushed stone ( $\breve{\mathrm{S} D})$ layer, or by a mechanically stabilised $25 \mathrm{~cm}$ aggregate (MSK) layer as well as by a 20 to $22 \mathrm{~cm}$ thick $\mathrm{CBGM} \mathrm{C}_{1,5 / 2}$.

It is logical that this knowledge can be used to solve decreases in a pavement's total thickness. This, however, is connected to a pavement's deterioration from frost penetration. The climate conditions in Slovakia are such that the pavement protection criterion (against frost penetration) is still in first place.

The paper was created with the support of the VEGA project 1/0501/17: Environmentally acceptable materials and technologies for traffic areas. 


\section{REFERENCES}

Gschwendt, I. (1999) Vozovky: konštrukcie a ich dimenzovanie (Pavements: Structures and Design). JAGA group, ISBN 8088905-14-1, Bratislava, Slovakia, 1999 (in Slovak).

Komacka, J. (2011) Change of Bearing Capacity Characteristics of Asphalt Pavement (2011) In: Komunikacie, 13 (3), pp. 52-55. Vol. 13, No. 3, 2011, University of Zilina, Slovakia, Copyright 2017 Elsevier B.V., SCOPUS, ISSN:1335-4205.

Molenaar, A. A. (1983) Structural Performance and Design of Flexible Road Construction. Delft University of Technology.

Team of authors (2010) $X V^{\text {th }}$ Seminar of Ivan Poliaček with international participation, Road Management and PPP projects. Proceedings, Kongres STUDIO, Ltd., ISBN 978-80-970356-4-6, Bratislava, Slovakia.

TPA, Ltd. (2009) Modely degradácie a degradačné funkcie drsnosti asfaltových vozoviek (Degradation Models and Degradation Functions of Roughness of Asphalt Pavements)., Bratislava, Slovakia (in Slovak).

Kolivoška, J. (2013) Najčastejšie použivané spôsoby opravy vozoviek regionálnych ciest (The Most Commonly Used Methods to Repair Regional Roads). In: XVIIIth Seminar of Ivan Poliaček with international participation "Obnova a rekonštrukcie cestných komunikácií - Rehabilitation and Reconstruction of Road Network“, Proceedings. Kongres STUDIO, Ltd., ISBN 978-8089565-12-2, Bratislava, Slovakia 2013, pp. 53 - 57.
Bures, P. - Fiedler, J. - Kaspar, J. - Sykora, M. - Hyzl, P. (2017) Performance Properties of Asphalt Mixes for Rich Bottom Layers (RBL), In: International Conference on Building Up Efficient and Sustainable Transport Infrastructure (BESTInfra), Book Series: IOP Conference Series-Materials Science and Engineering, Vol.: 236, Article No: UNSP 012004, Prague, Czech Republic, Sept. 21-22, 2017, WOS, DOI: 10.1088/1757-899X/236/1/012004.

Mondschein, P. et al. (2015) Konstrukce netuhých vozovek se směsmi VMT a RBL (Design of Flexible Pavements with High Modulus Mixtures and Rich Bottom Layer). In: $X^{\text {th }}$ Seminar of Ivan Poliaček with international participation "Sustainable Development of Road Construction", Proceedings. Kongres STUDIO, Ltd., ISBN 978-80-89565-21-4, Bratislava, Slovakia 2015, pp. $59-62$.

Gajewski, M. - Jemiolo, S. (2016) The Influence of Pavement Degradation Caused by Cyclic Loading on its Failure Mechanisms, In: Baltic Journal of Road and Bridge Engineering, Vol.: 11, No.: 3, pp. 179-187, WOS, DOI: 10.3846/bjrbe.2016.21, 2016. 